\title{
Eutanásia e sua relação com casos terminais, doenças incuráveis, estados neurovegetativos, estados sequelares graves ou de sofrimento intenso e irreversível e morte encefálica
}

\author{
The relationship between euthanasia and terminal cases, \\ incurable diseases, vegetative states, serious sequelar or \\ intense irreversible suffering conditions and brain death
}

\author{
Sergio Domingos Pittelli ${ }^{1}$, Reinaldo Ayer de Oliveira ${ }^{2}$
}

\begin{abstract}
Pittelli SD, Oliveira RA. Eutanásia e sua relação com casos terminais, doenças incuráveis, estados neurovegetativos, estados sequelares graves ou de sofrimento intenso e irreversível e morte encefálica. Saúde, Ética \& Justiça. 2009;14(1):32-9.

Resumo: Os autores traçam considerações a respeito dos conceitos de terminalidade, eutanásia e ortotanásia referindo-os aos vários estados clínicos relacionados às situações limítrofes da vida, apontando e dirimindo equívocos manifestados nos meios de comunicações e por formadores de opinião. Discutem a Resolução CFM 1805/2006 e o Código de Ética Médica (Resolução 1931/2009) demonstrando a relação dos respectivos conteú-dos normativos com os conceitos em apreço.
\end{abstract}

Descritores: Eutanásia. Estado vegetativo persistente. Morte encefálica. Ortotanásia. Casos Terminais.

A forma como a sociedade moderna trata a morte e os estados terminais está sofrendo um processo de profundas alterações. Ao velho paradigma "manter a vida a qualquer custo" como a suprema e única finalidade da Medicina, contrapõe-se um novo paradigma que questiona vigorosamente a antiga postura e caracteriza-se, entre outras medidas, por eleger a dignidade da pessoa humana como valor norteador das condutas em situações de terminalidade, entendendo-se por tal, a preocupação com a forma como se trata o doente terminal e as decisões e medidas que se tomam com relação ao momento final.

$\mathrm{Na}$ constelação de idéias que dá forma a esse novo paradigma, ao tradicionalmente conhecido conceito de eutanásia juntam-se novos conceitos: distanásia, mistanásia, ortotanásia e excesso terapêutico bem como obstinação terapêutica ou tratamento fútili ${ }^{1}$.

Em consonância com essa nova realidade, o Con-

1 Médico e advogado. Doutor em Ciências pelo Departamento de Fisiopatologia Experimental da Faculdade de Medicina da Universidade de São Paulo.

2 Docente do Departamento de Medicina Legal, Ética Médica e Medicina Social e do Trabalho da Faculdade de Medicina da Universidade de São Paulo e coordenador da Câmara Técnica de Bioética do Conselho Regional de Medicina de São Paulo.

Endereço para correspondência: Prof. Dr. Reinaldo Ayer de Oliveira, FMUSP. Instituto Oscar Freire. Av. Dr. Arnaldo, 455, Cerqueira César, São Paulo, SP. CEP 01246-903. E-mail: sergio @ pittelli.adv.br 
Pittelli SD, Oliveira RA. Eutanásia e sua relação com casos terminais, doenças incuráveis, estados neurovegetativos.

selho Federal de Medicina (CFM) emitiu, em novembro de 2006, a Resolução 1805/2006 cuja finalidade é orientar a conduta a ser tomada pelos médicos em situações clínicas consideradas terminais.

Compreensivelmente, as novas idéias não são assimiladas de pronto pela sociedade, não faltando exemplos de confusões entre os conceitos, das quais a mais importante refere-se às noções de terminalidade e ortotanásia, por um lado, confrontados com a idéia de eutanásia.

A imprensa é farta em exemplos de confusões dessa natureza. Em 04/07/2005, matéria em jornal de grande circulação ${ }^{2}$ cujo objeto era exatamente a supracitada Resolução, expunha como título "Eutanásia não fere ética médica, diz CRM", demonstrando, já no título, a confusão do jornalista entre terminalidade, único objeto da resolução, e eutanásia. No corpo da matéria, lê-se ainda, entre outras afirmações com sentido muito próximo a este: "Para advogados criminalistas, a medida não tem força de lei e não isenta o médico de uma ação por eutanásia". Na mesma matéria jornalística o Presidente da Comissão de Bioética e Biodireito da OAB-SP assim se expressou: "Não tem amparo legal nem força legal nenhuma. Os médicos não podem ser orientados a praticar um crime. Porque eutanásia, em qualquer modalidade, hoje é crime" ${ }^{3}$.

Embora no geral as matérias nos meios de comunicação demonstrem haver entendimento a respeito da diferença entre o conceito de eutanásia e de suspensão de procedimentos em casos terminais (comumente denominada ortotanásia), não são infreqüentes demonstrações de imprecisão de conceitos por parte da população, ou mesmo dos formadores de opinião, tais como as citadas acima.

Trazemos como exemplo, novamente, matéria jornalística de 02/09/05 ${ }^{4}$, a respeito de criança com doença degenerativa do sistema nervoso central, em fase terminal. Numa primeira referência, o texto registra a opinião de especialista em Medicina Legal que vê sem ressalva "a suspensão do esforço terapêutico" e, subseqüentemente, contrasta essa opinião com outra da mesma pessoa na qual esta expressa a concepção de que eutanásia é homicídio. No transcorrer do texto, entretanto, afirma ser o pai favorável à eutanásia e a mãe contrária, restabelecendo novamente a confusão de conceitos.

Como conseqüência, tanto o Ministério Público quanto a $O A B$ têm-se manifestado contrariamente à edição de textos que permitam a supressão (apenas e tão somente) de medidas que prolonguem inutilmente a vida ${ }^{3,5,6}$

Mesmo o entendimento (ou aparente entendimento?) da diferença entre os conceitos de eutanásia e ortotanásia (suspensão de medidas tipicamente classificáveis como esforço terapêutico inútil ou mesmo fútil) pode não ser suficiente para afastar a oposição a esta última.

Renato Marcão ${ }^{7}$, por exemplo, comentando o projeto de alteração do Código Penal em discussão no congresso, ao referir-se à ortotanásia (art. 121, $\S 4^{\circ}$ do projeto) afirma "não vejo motivos para a intervenção humana naquilo que nunca lhe coube determinar", traindo, a nosso ver, na forma como se expressa, a idéia de medida ativa, no sentido de suprimir algo por antecipação. Logo a seguir, afirma ainda: "De se salientar, ainda, que a ortotanásia não seria praticada por compaixão, para abreviar sofrimento físico insuportável, em razão de doença grave e em estado terminal. A meu ver, aquele que mata nos termos do $\S 4^{\circ}$ do art. 121 do anteprojeto não é menos homicida que aquele que o faz em conformidade com o $\S$ 3음 do mesmo dispositivo, e ambos, na essência, não se diferenciam dos que se amoldam ao caput do art. 121 do CP". Mais uma vez a forma de expressar-se trai a verdadeira concepção: para o ilustre jurista, a suspensão de medidas nos termos propostos por seus defensores é uma forma de matar e é indistinguível da eutanásia.

Essa concepção, por sua vez, é reforçada pelo inadequado uso de expressões como eutanásia ativa e eutanásia passiva ${ }^{8}$. Aliás, a esse respeito, na Resolução do CFM 1805/2006 não é citada nem mesmo a palavra ortotanásia, medida que segundo nosso entendimento é propositada e devida ao valor simbólico negativo associado mesmo a esse termo.

Em face das confusões reinantes a respeito dos conceitos envolvidos, o Ministério Público Federal, pela Procuradoria Regional dos Direitos do Cidadão da Secional do Distrito Federal (MPF) propôs Ação Civil Pública (ACP), com pedido liminar, contra o CFM para que seja suspensa a eficácia da Resolução 1805/2006, tendo efetivamente conseguido a suspensão temporária da vigência da resolução em apreço.

A petição inicial dessa ação é enorme e sua análise não caberia no tipo de texto em que se constitui este artigo, mas releva ressaltar, ainda que correndo o risco de pecar pela falta, que dois 
Pittelli SD, Oliveira RA. Eutanásia e sua relação com casos terminais, doenças incuráveis, estados neurovegetativos.

dos fundamentos mais importantes citados na peça são exatamente os conceitos de Marcão ${ }^{7}$ e $\mathrm{Campi}^{8}$, que são não apenas citados mas mesmo transcritos, demonstrando que o Autor da Ação Civil Pública, num certo sentido, ressente-se dos mesmos equívocos quanto aos conceitos.

Por tais motivos, entendemos ser importante uma espécie de "exegese" dos termos médicos envolvidos na discussão, com esclarecimento de seus respectivos conceitos, que vem a ser o que nos propomos a fazer no texto que segue associado ao final, a breve análise da Resolução do CFM 1805/2006 e do novo Código de Ética Médica, Resolução CFM 1931/2009.

Isso posto, registramos que pretendemos tecer considerações sobre a natureza dos seguintes conceitos médicos: coma, estado neurovegetativo persistente e coma irreversível, morte encefálica e morte (ou "morte circulatória"), eutanásia, distanásia, ortotanásia e estado terminal.

\section{Сома}

Coma é um estado clínico que se define, em termos comportamentais, pelo comprometimento do ciclo vigília-sono. Esse comprometimento traduz-se pela perda parcial ou total da consciência e conseqüentemente das funções da vida de relação. Uma afirmação categórica a respeito dessa condição clínica, que se pode fazer sem temor de errar, é que ninguém permanece eternamente em coma: ou se recupera (o que significa dizer, com certeza, apenas e tão somente que recuperará o ciclo vigília-sono) ou, se o agravo ao sistema nervoso foi muito grave, evoluirá para a morte, passando ou não pela fase denominada morte encefálica.

Nos casos em que houver recuperação, esta poderá dar-se com qualquer grau de seqüela, que dependerá também da gravidade da agressão sofrida, podendo inclusive não haver nenhum déficit residual.

Se, após consolidadas, as seqüelas forem de tal monta e conformação que se caracterizem pela inexistência de comportamentos referentes à vida de relação (tecnicamente denominada "aperceptividade"), permanecendo apenas as funções vegetativas (tecnicamente denominadas "reatividade"), apresentase o que se denomina em medicina, o estado neurovegetativo persistente (ENP).

\section{Estado NEUROVEGETATIVO PERSISTENTE}

O ENP é uma condição neurológica na qual, em função da gravidade do insulto sofrido pelo sistema nervoso central, as funções da vida de relação são abolidas. Os pacientes apresentam apenas reações neurovegetativas a estímulos dolorosos, tais como aumento da pressão arterial, freqüência cardíaca, freqüência respiratória, etc., bem como a integridade do componente reflexo de funções viscerais, tais como diurese e evacuação, sem, entretanto, o elemento de controle voluntário sobre elas. Não apresentam nenhum sinal de que detectam qualquer estímulo que não seja doloroso e de contato direto com o corpo, tais como visual e auditivo, e muito menos que consigam agregar qualquer significado simbólico a eles ou de qualquer forma a eles reagir. Daí o termo aperceptividade aplicados aos pacientes nessa condição.

Uma característica desse grupo de pacientes é que apresentam o ciclo vigília-sono preservado, motivo pelo qual não são mais considerados pacientes em coma, embora sejam confundidos pelo leigo que comumente se refere a essa condição clínica como "coma permanente".

A importância desse grupo, para as finalidades deste texto, é que também são confundidos pelo leigo com quadros de "morte encefálica", dando vezo à crença de que este último quadro pode se mostrar reversível (ou pelo menos perenizável), circunstância que gera enormes problemas na área de doação para transplantes.

Podemos adiantar neste ponto que os pacientes desse grupo, "neurovegetativo", não são considerados "terminais" e não estão sujeitos a qualquer consideração sobre abreviação da vida, pelo menos não nos termos da supracitada Resolução 1805/2006. Com efeito, são pessoas que podem respirar por conta própria e se eventualmente não o fazem, não é por problemas neurológicos, mas sim do sistema respiratório - infecções, por exemplo e reversíveis. Demandam obrigatoriamente apenas e tão somente aquilo que a ausência de vida de relação não Ihes permite obter por conta própria: higiene, alimentação e "repouso", entendido este último como a capacidade de mudar o decúbito ou adotar posições que permitam a manutenção do estado de trofia de músculos, articulações e pele, de modo a que, por exemplo, não apresentem escaras nem anquiloses. 
Pittelli SD, Oliveira RA. Eutanásia e sua relação com casos terminais, doenças incuráveis, estados neurovegetativos.

\section{Coma irReversível}

O terceiro conceito a ser esclarecido, é o chamado "coma irreversível". Segundo nosso entendimento, há duas entidades que o leigo associa ao conceito em questão.

Por um lado, há os que o confundem com o estado neurovegetativo persistente (que se caracteriza pela perenidade e que pode, em raros casos, voltar a apresentar vida de relação, ainda que precária), admitindo equivocadamente tratar-se este último de coma, conforme dito acima.

Por outro lado, há os que o associam à morte encefálica (no que não estão de todo errados), havendo ainda aqueles que confundem os três conceitos. Na verdade, a melhor aproximação para o termo é mesmo morte encefálica, admitindo-se essa condição como um coma que é irreversível mas, diferentemente do ENP, não perenizável, pois todo paciente portador de morte encefálica sofrerá parada cardiorrespiratória inexoravelmente em tempo em geral não superior a 96 horas

\section{MoRTE ENCEFÁLICA}

A morte encefálica vem a se configurar situação definitiva, subseqüente à instalação de quadros gravíssimos de coma, na qual se dá a completa interrupção da circulação sanguínea do encéfalo com a morte de suas células, caracterizando-se, além da inexistência de qualquer comportamento referente à vida de relação, também pela inexistência de qualquer forma de comportamento vegetativo. Esse quadro, descrito por Mollaret e Goulon ${ }^{9} \mathrm{em}$ 1959, é cientificamente considerado como igual à morte e juridicamente considerado como tal pelo ordenamento jurídico brasileiro.

Com efeito, a Lei no 9.437/1997 ("Lei dos Transplantes") delegou ao CFM a competência para definir o conceito de morte encefálica e este assim o fez na Resolução 1480/1997, estabelecendo, nela, os critérios de diagnóstico.

A interrupção, nesses casos, das medidas destinadas a manter artificialmente a circulação sanguínea e a respiração não são, portanto, consideradas medidas que abreviam a vida, porque a pessoa é considerada morta. Posteriormente, - CFM editou a Resolução no 1.826/07 regulamentando a suspensão dos procedimentos de suportes terapêuticos quando determinada a morte encefálica em não-doador de órgãos, tecidos e partes do corpo humano para fins de transplante, ampliando as hipóteses fáticas de aplicação do conceito de morte encefálica.

O reconhecimento científico e legal do conceito de morte encefálica não fez outra coisa que reforçar a noção já do conhecimento científico desde pelo menos a primeira metade do século passado, de que a morte não é um fenômeno "pontual" que se dá no momento da parada do coração e da circulação sanguínea (como sempre se entendeu, desde os albores da civilização), pois já era do conhecimento dos estudiosos que as células dos diversos tecidos do corpo morrem em momentos diversos, após a parada da circulação. Com o conceito de morte encefálica, a ciência estabeleceu que o momento do início da morte das células (no caso, as células do encéfalo) pode até ser anterior à parada do coração.

\section{EUTANÁSIA}

A definição etimológica de eutanásia é de todos conhecida; avançando além da definição estritamente lingüística, cumpre aduzir que integra necessariamente a conduta daquele que a pratica o animus de diminuir o sofrimento do doente, pois de outra forma, tratar-se-ia, com grande possibilidade, simplesmente de forma qualificada de homicídio, seja por impossibilidade de defesa da vítima, seja por justificada confiança. Com efeito, em países que adotam a eutanásia considera-se que a intenção daquele que provoca a morte deve ser livrar aquele que está para morrer de uma condição insuportável: entende-se com isso, em geral, sofrimentos intoleráveis ou uma situação de indignidade e de desamparo extremo provocado pela doença.

É elemento fundamental da definição, também, que seja tomada alguma medida ativa no sentido de abreviar a vida do paciente, além do tempo que ele levaria para morrer espontaneamente.

\section{Distanásia}

A moderna bioética cunhou o conceito de distanásia ${ }^{10}$ que, em breves palavras, pode ser conceituada como a condição em que "a tecnologia médica é usada para prolongar penosa e inutilmente o processo de agonizar e morrer" (p. 172). Ainda nas palavras deste mesmo autor, "enquanto na 
Pittelli SD, Oliveira RA. Eutanásia e sua relação com casos terminais, doenças incuráveis, estados neurovegetativos.

eutanásia a preocupação maior é com a qualidade de vida remanescente, na distanásia a tendência é de se fixar na quantidade desta vida e de investir todos os recursos possíveis em prolongá-la ao máximo".

Além da característica acima apontada, de prolongador do processo de agonizar e morrer, ou mesmo em função dela, o conceito de distanásia é também associado ao poder material da tecnologia moderna colocada à disposição da Medicina, ao distanciamento entre o médico e o paciente e à impessoalização do tratamento oferecido aos seres necessitados nas grandes unidades hospitalares modernas e ao distanciamento entre família e morituro, tornando solitários os últimos momentos da vida.

Costuma-se também qualificar o tratamento ministrado nestas condições de "fútil" ou mesmo "inútil", ou ainda "obstinação terapêutica", vez que seu único resultado é prolongar o sofrimento.

As circunstâncias assim criadas mobilizaram setores importantes da sociedade, inclusive a Igreja Católica, a posicionar-se com relação ao problema, fazendo-o, no geral, contra.

É esta também origem da preocupação do CFM ao emitir a Resolução sobre a terminalidade da vida.

\section{Ortotanásia}

O pleno entendimento do conceito de ortotanásia implica em considerar duas ordens de idéias, uma de natureza ética e outra de natureza médica Reportando-nos à primeira, evocamos mais uma vez Leonard M Martin, segundo quem se impõe uma importante mudança de conceito no que respeita ao que se entende por saúde. Refere-se ele ao fato de que, dentro da perspectiva estritamente curativa da medicina, é impossível falar em cura de doentes terminais (seria mesmo uma contradição em termos), mas se entendermos saúde como "estado de bem estar" (definição inclusive já existente e conhecida, correspondente à estrutura triádica da OMS à qual o autor aduz o bem estar espiritual) passa a haver sentido no falar em saúde (e não propriamente cura, aduzimos) de pacientes terminais, pois o compromisso, nessa situação, mudaria seu foco principal da cura da doença para o cuidado com o bem estar do doente e de sua família no contexto da terminalidade.

Conceito idêntico foi registrado em relatório de um grupo que se reuniu sob o patrocínio do CRE-
MESP"1: "Teria a ação médica nos casos terminais a finalidade precípua de prestar os cuidados em vez de insistir na cura do paciente. Ou seja, tentar dar atenção à pessoa que está nesse estado e não à doença que a pessoa carrega consigo".

Voltando ao autor supracitado, essa mudança de postura e de conceitos permite falar numa "arte de bem morrer" que evita aquilo que denomina "as ciladas" da eutanásia e da distanásia.

Para o correto entendimento dos aspectos médicos da ortotanásia, é útil tratarmos antes do conceito de terminalidade da vida. Das manifestações de setores médicos ligados aos Conselhos a respeito do tema em apreço, que temos podido apreciar, extrai-se, s.m.j., a impressão de que há tendência a não definir terminalidade.

Esta postura está manifestada de modo expresso no relatório da reunião patrocinada pelo CREMESP acima citada e o CFM, tanto no texto, quanto na exposição de motivos da Resolução 1805/2006, não define o conceito. Neste último, consta a seguinte afirmação: "A terminalidade da vida é uma condição diagnosticada pelo médico diante de um enfermo com doença grave e incurável". Depreende-se daí a natureza pelo menos parcialmente casuística do conceito: o diagnóstico será dado caso a caso, segundo os conceitos médicos aplicáveis a cada situação concreta.

Enunciados os elementos que compõem o conceito de terminalidade, e já delineados acima os conceitos de coma, estado neurovegetativo persistente e morte encefálica, podemos voltar agora aos aspectos médicos da ortotanásia.

Isso posto, deve-se entender por ortotanásia, do ponto de vista estritamente médico, uma forma de proceder que se constitui de um elemento positivo e alguns elementos negativos.

Pelo primeiro exige-se que se aplique exclusivamente a casos graves e em fase terminal.

E é esta primeira condição que nos remete aos critérios negativos: não se aplica a casos de estados neurovegetativos persistentes porque esses casos não são terminais; não se aplica aos casos de coma em geral, porque tais casos, são, em princípio, reversíveis, ainda que possam resultar em um quadro de estado neurovegetativo persistente; não se aplica à morte encefálica porque esta é, legal e medicamente, considerada como morte e, portanto, em tese, não é mais um quadro terminal, a não ser no sentido literal do conceito. 
Pittelli SD, Oliveira RA. Eutanásia e sua relação com casos terminais, doenças incuráveis, estados neurovegetativos.

Também não se aplica o conceito de ortotanásia a casos que se restringem a sofrimento intenso de qualquer de natureza, seja dor (ainda que originada em doença mortal mas ainda em fase não terminal) ou desconforto existencial, como casos de pacientes acamados cronicamente por seqüelas de doenças não mortais, tais como os tetraplégicos.

Neste ponto torna-se oportuno lembrar o rumoroso caso da jovem italiana Eluana Englaro, que, vitimada num acidente de automóvel, permaneceu em estado neurovegetativo persistente por 17 anos. Seu pai conseguiu em sede judicial que fossem suspensas as medidas de suporte da vida. Não se tratava de caso terminal. Aliás, conforme pudemos registrar com dados dos meios de comunicação, o único cuidado que foi suspenso foi a alimentação por sonda, vez que ela respirava por conta própria e a necropsia revelou que a morte se deu por desidratação, conseqüência da suspensão da alimentação. Caso idêntico é o da americana Terry Schiavo.

Resumindo, podemos dizer que a ortotanásia diferencia-se da eutanásia porque não implica em tomar medidas ativas no sentido de abreviar a vida, como se deu no caso da jovem italiana e da americana.

A grande característica do comportamento médico nas situações em que se poderia usar o termo ortotanásia é de suspender apenas e tão somente as medidas que se enquadrariam no conceito de "obstinação terapêutica" (que é, em última análise, o elemento que dá vezo à distanásia), focando sua ação na manutenção do bem estar do paciente, tomando todas as medidas necessárias para este fim.

\section{A Resolução CFM 1805/2006}

Feitas estas considerações, analisemos agora a Resolução 1805/2006 do CFM, cujo texto transcrevemos.

Art. 1o É permitido ao médico limitar ou suspender procedimentos e tratamentos que prolonguem a vida do doente em fase terminal, de enfermidade grave e incurável, respeitada a vontade da pessoa ou de seu representante legal.

$\S 1$ 으 $\mathrm{O}$ médico tem a obrigação de esclarecer ao doente ou a seu representante legal as modalidades terapêuticas adequadas para cada situação.

$\S 2^{\circ}$ A decisão referida no caput deve ser fundamentada e registrada no prontuário.

$\S$ 3ํ́ É assegurado ao doente ou a seu representante legal o direito de solicitar uma segunda opinião médica.
Art. $2^{\circ} \mathrm{O}$ doente continuará a receber todos os cuidados necessários para aliviar os sintomas que levam ao sofrimento, assegurada a assistência integral, o conforto físico, psíquico, social e espiritual, inclusive assegurando-lhe o direito da alta hospitalar.

Art. 3ำ Esta resolução entra em vigor na data de sua publicação, revogando-se as disposições em contrário.

Um primeiro dado de importância é que seu artigo primeiro restringe a abrangência da norma ao âmbito dos casos em fase terminal, segundo conceituado na exposição de motivos e acima, neste texto. Em outras palavras, não se trata de eutanásia no sentido em que este termo é normalmente entendido, que incluiria as demais entidades acima discutidas.

Outro dado de interesse é que este primeiro artigo tem natureza apenas permissiva, ou seja, não obriga o médico, o que de resto seria incompatível com a natureza do assunto e a competência normativa do CFM quanto à matéria.

Por outro lado, prescreve a norma a obrigatoriedade do esclarecimento consentido $\left(\S 1^{\circ}\right)$, do registro em prontuário $\left(\$ 2^{\circ}\right)$ e da possibilidade de o paciente/familiar obter uma segunda opinião $\left(\S 3^{\circ}\right)$.

Finalmente, em seu segundo artigo, determina que todos os demais cuidados devem ser mantidos, afastando assim a possibilidade de que tal atitude seja entendida como "abandono" e reiterando o elemento de "cuidado com o bem estar do paciente".

É interessante notar que tanto no texto da resolução quanto da exposição de motivos não se encontra a palavra "ortotanásia". Suspeitamos que essa atitude seja propositada, pois mesmo com todas as considerações que se têm feito a respeito da diferença entre eutanásia e ortotanásia, podese afirmar que este último "herdou" por assim dizer, pelo menos em parte, o valor simbólico negativo do primeiro.

A análise da norma em apreço deixa clara a delimitação das hipóteses fáticas abrangidas e a correspondente "liberdade de ação" permitida ao médicos, possibilitando concluir que não se justificam os temores reportados na primeira parte deste texto.

Não obstante, cumpre lembrar, ao terminar este tópico, que essa Resolução acha-se suspensa por força de medida liminar obtida em Ação Civil Pública levada a efeito na Circunscrição Judiciária Federal do Distrito Federal. 
Pittelli SD, Oliveira RA. Eutanásia e sua relação com casos terminais, doenças incuráveis, estados neurovegetativos.

\section{A resolução CFM 1931/09 e o novo Código de Ética MÉDICA}

O novo Código de Ética Médica, aprovado pela Resolução CFM 1.931/09, que entrará em vigor após a data de 22 de março de 2010, inovou ao abordar pela primeira vez o tema terminalidade da vida, tratada em dois dispositivos:

Capítulo I - Princípios Fundamentais:

XXII - Nas situações clínicas irreversíveis e terminais, o médico evitará a realização de procedimentos diagnósticos e terapêuticos desnecessários e propiciará aos pacientes sob sua atenção todos os cuidados paliativos apropriados.

Capítulo V - Relação com Pacientes e Familiares É vedado ao médico:

Art. 41 - Abreviar a vida do paciente, ainda que a pedido deste ou de seu representante legal.

Parágrafo único. Nos casos de doença incurável e terminal, deve o médico oferecer todos os cuidados paliativos disponíveis sem empreender ações diagnósticas ou terapêuticas inúteis ou obstinadas, levando sempre em consideração a vontade expressa do paciente ou, na sua impossibilidade, a de seu representante legal.

Constata-se que os dois dispositivos acima transcritos reproduzem, em conjunto, todo o conteúdo da Resolução 1805/2006. Não se trata, entretanto, de mera repetição. A inclusão dos artigos em apreço no texto do CEM apresenta pelo menos duas implicações importantíssimas.

A primeira, decorrente do art. XXII, é que o respeito à situação do doente em fase terminal foi erigida à condição de Princípio Fundamental, circunstância não proporcionada pela Resolução e que reforça o valor simbólico do conceito.

A segunda é que a inclusão do parágrafo único do artigo 41 (antigo 66) ressalta a diferença entre o conteúdo do caput (que veda a eutanásia) e do dispositivo (que prescreve cuidados paliativos), reforçando assim a idéia de que cuidado paliativo em casos terminais não é eutanásia.

Por último, a expressão "deve o médico", contida no parágrafo único do art. 41 deve ser entendida como tendo sentido permissivo e não imperativo (ambos admitidos pelo verbo "dever"), não só por ser essa a tradição ideológica do CFM no assunto, mas também porque, o contrário violaria a competência normativa do órgão, conforme já explanado acima.

Os autores esperam que tais dispositivos do novo CEM ajudem a aplacar os temores manifestados pela sociedade com referência à terminalidade.

Pittelli SD, Oliveira RA. The relationship between euthanasia and terminal cases, incurable diseases, vegetative states, serious sequelar or intense irreversible suffering conditions and brain death. Saúde, Ética \& Justiça. 2009;14(1):32-9

AвstRAct: The authors address concepts concerning terminal state, euthanasia and orthothanasia as well as the relations between these concepts and the clinical conditions related to next-to-death situations, by pointing out and elucidating mistakes from the media and opinion makers. Resolution CFM 1805/2006 and the Medical Code of Ethics (Resolution CFM 1931/2009) are discussed from the point of view of the relations between their normative content and the above cited concepts.

KeYwords: Euthanasia. Persistent vegetative state. Brain death. Orthothanasia. Terminal states.

\section{REFERÊNCIAS}

1. Martin L. Eutanásia e Distanásia In: Costa SIF, Garrafa V, Oselka G, coordenadores. Iniciação à bioética. Brasília, DF: Conselho Federal de Medicina; 1998. p. 171-192

2. Collucci $C$. Eutanásia não fere ética médica, diz CRM. [Folha de S. Paulo, Cotidiano online]. 4 jul. 2005 Disponível em: http://www1.folha.uol.com.br/fsp/ cotidian/ff0407200501.htm
3. Collucci C. Médico pode limitar ajuda a doente terminal. [Folha de S. Paulo, Cotidiano online]. 10 nov. 2006. Disponível em: http://www1.folha. uol.com.br/folha/cotidiano/ult95u128054.shtmINO $10 / 11 / 2006$

4. Médico defende fim do tratamento de Jhéck. [Folha de S. Paulo, Cotidiano online]. 2 set. 2005. Disponível em: http://www1.folha.uol.com.br/fsp/cotidian/ ff0209200521.htm

5. CFM desobriga médico de manter vivo paciente termi- 
Pittelli SD, Oliveira RA. Eutanásia e sua relação com casos terminais, doenças incuráveis, estados neurovegetativos.

nal. [Terra Notícias online]. 28 jul. 2006; Disponível em: $\quad$ http://noticias.terra.com.br/ciencia/interna/ 0,,Ol1081931-El298,00-CFM+desobriga+medico+de +manter+vivo+paciente+terminal.html

6. Mariz R. Ortotanásia será adotada. Correio Braziliense, Brasília, DF, 29 jul. 2006.

7. Marcão R. Homicídio eutanásico: eutanásia e ortotanásia no anteprojeto do código Penal. [Jus Navegandi online]. Teresina, n.57, jul. 2002. Disponível em: http://jus2.uol.com.br/doutrina/texto. asp? $\mathrm{id}=2962$

8. Campi S. O valor intrínseco da vida e a autonomia: reflexões sobre a eutanásia. [dissertação].
Florianópolis, SC: Departamento de Filosofia da Universidade Federal de Santa Catarina; 2004.

9. Mollaret O, Goulon M. Le coma dépassé. Rev Neurologique. 1959;101:3-15.

10. Martin LM. Eutanásia e distanásia. In: Costa SIF, Garrafa V, Oselka G. Iniciação á bioética. Brasília: CFM; 1998. p. 171-92.

11. Rosenthal C, coordenação. Relatório da oficina de São Paulo. In: Oselka G, Oliveira RA, coordenação. Doente terminal. Destino de pré-embriões. Clonagem. Meio ambiente. São Paulo: Conselho Regional de Medicina do Estado de São Paulo; 2005. p. 11. (Cadernos de Bioética do CREMESP).

Artigo recebido em: 14/04/2009.

Aprovado em: 07/05/2009. 